\title{
Vascular assessment of the right internal jugular vein in low birth weight newborns
}

\author{
Fernando Montes-Tapia ${ }^{1}$, Antonio Rodríguez-Taméz ${ }^{1}$, Adolfo Hernandez-Garduño ${ }^{1}$, Itzel Barreto-Arroyo ${ }^{1}$, Isaías \\ Rodríguez-Balderrama ${ }^{1}$, Manuel de la O-Cavazos ${ }^{1}$, and José Quero ${ }^{2}$ \\ ${ }^{1}$ Departamento de Pediatría, Hospital Universitario "Dr. José E. González", Universidad Autónoma de Nuevo León, Monterrey, México, \\ ${ }^{2}$ Departamento de Pediatría, Universidad Autónoma de Madrid, Madrid, España
}

\begin{abstract}
Objective: To determine the dimensions and depth of the right internal jugular vein (RIJV) in low birth weight newborns by ultrasound and assess the differences in weight and determine the relationship of the vein with the carotid artery.

Method: We performed a vascular assessment of the RIJV in 100 low birth weight newborns. The subjects were divided into three groups, low birth weight (LBW) newborns, $<2500$ g; very low birth weight (VLBW) newborns, $<1500 \mathrm{~g}$; and extremely low birth weight (ELBW) newborns $<1000 \mathrm{~g}$.

Results: Of the newborns, 39\% had LBW, 33\% had VLBW, and 28\% had ELBW. The medians were gestational age 31 weeks, weight $1300 \mathrm{~g}$, anteroposterior diameter of the RIJV $2.2 \mathrm{~mm}$, and the distance from the skin-RIJV $3.6 \mathrm{~mm}$. In LBW newborns, the median anteroposterior diameter of RIJV was $2.7 \mathrm{~mm}$; in LBW newborns 2.2; in ELBW newborns $1.9(p<0.001)$; the median distance from skin to RIJV for LBW newborns was $4.1 \mathrm{~mm}$; for VLBW newborns, 3.6 and for ELBW newborns $2.9(p<0.01)$; differences that were statistically significant.

Conclusions: In low birth weight newborns, the diameter and depth of the RIJV is directly proportional to the weight of the subjects studied.
\end{abstract}

\author{
Keywords \\ Internal jugular vein, low-birth weight, \\ neonates
}

\author{
History \\ Received 11 January 2013 \\ Accepted 13 March 2013 \\ Published online 2 May 2013
}

\section{Introduction}

A central venous access is frequently mandatory in the care of a premature newborn. In this type of patients, venous access sometimes seems impossible due to the size of the infant or because other sites have already been used or are unavailable (umbilical, peripheral vessels, etc.). In these cases, central venous access becomes a necessary option. The internal jugular vein provides a predictable path for central venous cannulation, although it is more difficult to cannulate in infants than in adults and even more difficult the smaller the newborn. Also, complications in pediatric patients are greater [1-3].

The placement of an intravascular catheter is the most frequently invasive procedure performed in the intensive care unit [4,5]. To secure insertion of a central venous catheter (CVC) a complete medical history, physical examination, knowledge of the clinical needs of the patient, and finally the choice of body area for insertion, are required. After considering these factors, location of the vein is usually performed by palpation and anatomical references. However, correct placement of the catheter especially in small

Address for correspondence: Fernando Montes-Tapia, MD, PhD, Cirugía Pediátrica, Hospital Universitario “Dr. José E. González”, Universidad Autónoma de Nuevo León, Av. Madero y Gonzalitos s/n, Monterrey, N.L. México. E-mail: fernando.montestp@uanl.edu.mx infants, can be technically difficult and associated with potential complications. This is because the vein diameter, its depth, its location with regard to the accompanying arteries, and its patency are unknown. Vascular assessment is a convenient procedure that can be performed when anatomical landmarks are not enough $[4,6]$.

The aim of this study was to determine, by ultrasound, the dimension, depth, and patency of the right internal jugular vein (RIJV) in low birth weight newborns and report if any difference according to weight of the subjects exists, as well as determining the relationship of the vein with the carotid artery (CA).

\section{Method}

After obtaining informed parental consent, RIJV catherization was performed in 100 newborns weighing $<2500 \mathrm{~g}$ treated at the Neonatal Intensive Care Unit of the "Dr. José E. González" University Hospital in Monterrey, Mexico from August 2009 to December 2011.

Patients were classified into three groups according to their weight at the time of CVC placement: low birth weight (LBW, $<2500 \mathrm{~g}$ ), very low birth weight (VLBW, $<1500 \mathrm{~g}$ ), and extremely low birth weight (ELBW, <1000 g) [7].

The variables studied were gestational age, weight, gender, anteroposterior diameter of the RIJV, distance from the skin to the anterior wall of the vein, and the location of the RIJV in relation to the CA. 


\section{Technique}

Vascular assessment of the RIJV by ultrasound was done prior to the placement of the CVC. Sedation with $100 \mathrm{mcg} / \mathrm{kg}$ intravenous boluses of midazolam was used to reduce stress and nociceptive stimulation. During sedation patients were closely monitored. The patient was then placed supine with a $40^{\circ}$ rotation and fixation of the head contralateral to the site of the puncture and the assessment of the RIJV was performed.

The principal investigator (F. M. T.) conducted a vascular assessment of the RIJV in all newborns using a MicroMaxx portable ultrasound with a 4-8 Mhz transducer (Sonosite, Inc., Bothell, WA).

Measurement of the anteroposterior diameter of the RIJV was made at the level of the cricoid during inspiration; the distance from the skin to the anterior wall of the vein was also determined. Measurement was performed with the transducer placed transversely in the direction of the vessel, short-axis view (SAX), so the RIJV is seen cross-sectionally.

\section{Statistical analysis}

A specific database was designed in Excel 2008 to capture all information related to the variables of interest. Statistical analysis was performed with IBM Statistics 19 for Windows.

Continuous variables were reported according to their distribution, measures of central tendency, and dispersion; nominal or categorical variables were reported as proportions.

A stratified analysis by weight was performed classifying newborns into the following groups: LBW, $<2500 \mathrm{~g}$; VLBW, $<1500$ g; ELBW, $<1000 \mathrm{~g}$.

For the variable RIJV anteroposterior dimension, a comparative analysis was carried out according to the weight of the subjects using the Mann-Whitney test, considering differences with a $p$ value of $<0.05$ as statistically significant.

\section{Results}

During the study period, vascular assessment of the RIJV was done in 100 infants weighing less than $2500 \mathrm{~g}$. The median gestational age was 31 weeks (range 25-40). Median weight was $1300 \mathrm{~g}$ (range 540-2480). Of the subjects, 39\% were LBW, 33\% VLBW, and 28\% ELBW. There were 53\% female patients and $47 \%$ male patients. Newborns were mechanically ventilated in $73 \%$ (Table 1).

\section{Global vascular parameters}

All RIJVs were patent by ultrasound. In the vascular ultrasound measurements of the RIJV, a bimodal distribution of the variable was observed (Figure 1) with a transverse median anteroposterior diameter of $2.2 \mathrm{~mm}$ (range 1.2-4.5) being found. The median distance from the skin to the anterior wall of the RIJV was $3.6 \mathrm{~mm}$, with a range of 1.5-6.8 (Table 1).

\section{Data on the relationship of the CA and the RIJV}

During vascular assessment, it was found that the most frequent relationship of the RIJV with respect to the CA was a lateral localization in 69\%; an anterolateral location in $21 \%$; an anterior location in 7\%, and an anteromedial location in 3\% (Figure 2).

\section{Stratified analysis by age group}

We analyzed the characteristics of weeks of gestation, weight, gender, and mechanical ventilation stratified by group.

The comparison by weight of the subjects showed a statistically significant difference $(p<0.001)$ between LBW compared with VLBW and ELBW. As expected, LBW newborns had a greater gestational age, weight, and RIJV diameter. With regard to the distance from the skin to the

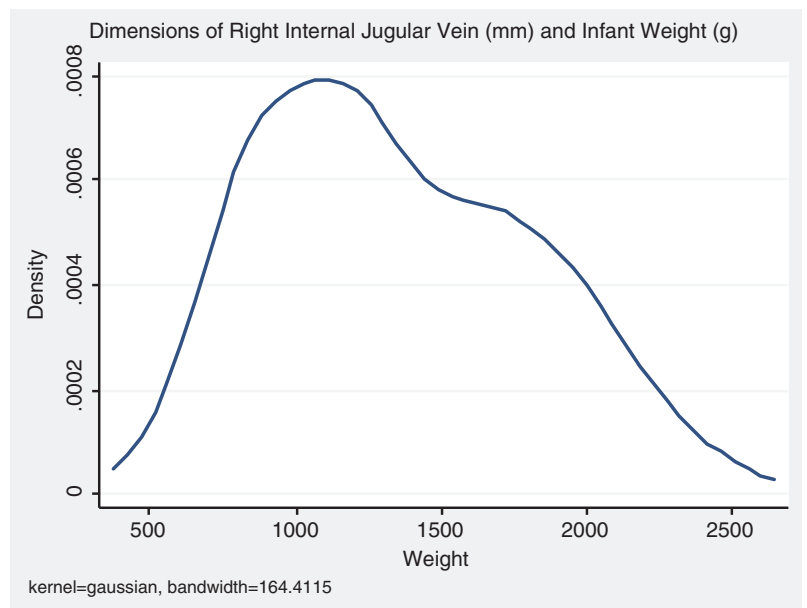

Figure 1. Dimensions of right internal jugular vein and infant weight.

Table 1. General characteristics of low birth weight newborns and differences according to weight of newborns.

\begin{tabular}{|c|c|c|c|c|}
\hline Variable & $\begin{array}{c}\text { Total } \\
(n=100)\end{array}$ & $\begin{array}{c}\text { LBW } \\
(n=39)\end{array}$ & $\begin{array}{c}\text { VLBW } \\
(n=33)\end{array}$ & $\begin{array}{c}\text { ELBW } \\
(n=28)\end{array}$ \\
\hline Weeks of gestation, median (range) & $31(25-40)$ & $35(21-40)$ & $31(26-38) *$ & $28(25-36) \ddagger$ \\
\hline Female, $n(\%)$ & 53 & $19(48.7)$ & $18(54.5)$ & $16(57.1)$ \\
\hline Mechanical ventilation (\%) & 73 & $20(51.3)$ & $26(78.8)$ & $27(96.4)$ \\
\hline Median AP diameter RIJV, mm (range) & $2.2(1.2-4.5)$ & $2.7(1.3-4.5)$ & $2.2(1.3-3.4)^{*}$ & $1.9(1.2-2.8)$ \\
\hline Mean AP diameter RIJV, mm (SD) & $2.59(0.68)$ & $2.81(0.75)$ & $2.26(0.51)$ & $1.94(0.34)$ \\
\hline
\end{tabular}

AP, anteroposterior; LBW, low birth weight newborns; VLBW, very low birth weight newborns; ELBW, extremely low birth weight newborns; RIJV, right internal jugular vein.

${ }^{*} p<0.001$ in comparison with LBW newborns.

$\dagger p<0.001$ in comparisons with VLBW newborns.

$\ddagger p<0.004$ with regard to LBW newborns.

$\uparrow p<0.007$ in comparison with VLBW newborns. 
RIJV only differences in the LBW group were found compared with the group of ELBW. We observed an inverse relationship between ventilation and weight at the time of CVC placement (Table 1).

Regarding vascular parameters in the groups studied we observed the following:

\section{LBW $(<2500 \mathrm{~g})$}

The median RIJV anteroposterior diameter was $2.7 \mathrm{~mm}$ (range 1.3-4.5) and the median distance from the skin to the vein, $4.1 \mathrm{~mm}$ (1.8-6.8; Figure 3A and Table 1).

In $28 \%$ of the LBW newborns, the relationship of the RIJV with respect to the CA corresponded to the lateral position in 24 patients $(61.5 \%$; Table 2$)$.

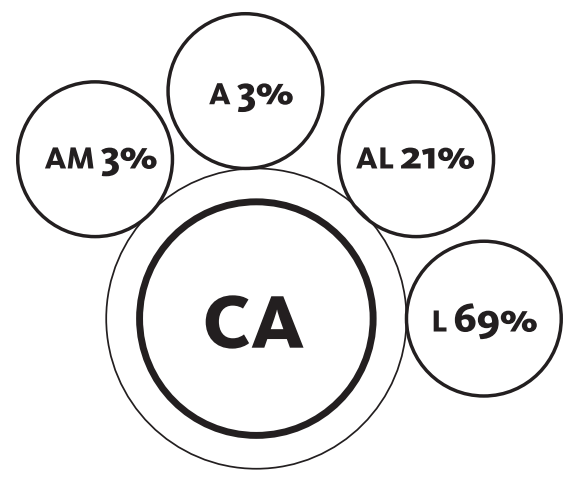

\section{Posterior}

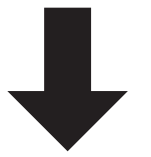

Figure 2. Relationship of the carotid artery and the right internal jugular vein. CA: carotid artery, L: lateral, AL: anterolateral, A: anterior, AM: anteromedial.

\section{$\operatorname{VLBW}(<1500 \mathrm{~g})$}

The median anteroposterior diameter of the RIJV was $2.2 \mathrm{~mm}$ (1.3-3.4) and the distance from the skin to the vein was $3.6 \mathrm{~mm}$ (2.3-5.6; Figure 3B and Table 1).

The relationship of the RIJV with regard to the CA corresponded to the lateral position in $22(66.7 \%$; Table 2$)$.

\section{$\operatorname{ELBW}(<1000 \mathrm{~g})$}

The median anteroposterior diameter of the RIJV was $1.9 \mathrm{~mm}$ (1.2-2.8) and the distance from the skin to the vein was $2.9 \mathrm{~mm}$ (1.5-5.7; Figure 3C and Table 1).

The relationship of the RIJV with regard to the CA corresponded to the lateral position in 23 (82.1\%; Table 2).

\section{Discussion}

The anteroposterior diameter of the RIJV presented a bimodal distribution, which is why it was considered appropriate to report the median of the anteroposterior diameter and its

Table 2. Relationship of the RIJV with the CA.

\begin{tabular}{lcccc}
\hline & Anteromedial & Anterior & Anterolateral & Lateral \\
\hline LBW & 1 & 6 & 8 & 24 \\
VLBW & 1 & 0 & 10 & 22 \\
ELBW & 1 & 1 & 3 & 23 \\
Total & 3 & 7 & 21 & 69 \\
\hline
\end{tabular}

LBW, low birth weight newborns; VLBW, very low birth weight newborns; ELBW, extremely low birth weight newborns, $n=100$.
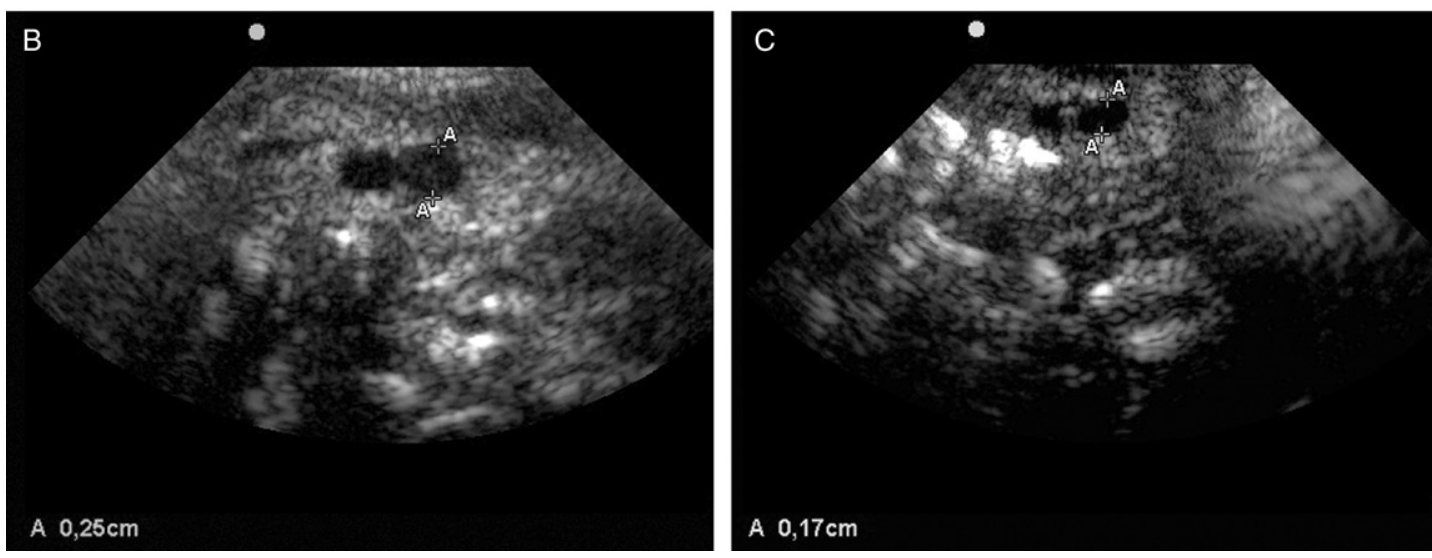

Figure 3. (A) Anteroposterior diameter of the right internal jugular vein $(\mathrm{A}-\mathrm{A}=2.9 \mathrm{~mm})$ in a newborn of $1680 \mathrm{~g}$. Anterior location of the right internal jugular vein in relation to the carotid. (B) Anteroposterior diameter of the right internal jugular vein $(\mathrm{A}-\mathrm{A}=2.5 \mathrm{~mm})$ in a newborn of $1190 \mathrm{~g}$. (C) Anteroposterior diameter of the right internal jugular vein $(\mathrm{A}-\mathrm{A}=1.7 \mathrm{~mm})$ in a newborn of $690 \mathrm{~g}$. 
range, instead of the mean and standard deviation as measures of central tendency and distribution. The low birth weight newborns included in this study had a median anteroposterior diameter of the RIJV of $2.2 \mathrm{~mm}$ (1.2-4.5). This bimodal distribution of the AP diameter was an unexpected finding and at this time we have found no explanation for this.

It is important to mention that according to the weight of the subjects, differences in the RIJV AP diameters between the groups (LBW, VLBW, and ELBW) were found with a statistically significant difference being present in LBW newborns in comparison with VLBW and ELBW newborns.

In a pathological study of neonates less than $1000 \mathrm{~g}$, Eifinger et al. [8] reported RIJV diameters of $4.1 \pm 0.8 \mathrm{~mm}$. These dimensions are greater than in our population. These differences could be explained because the measure reported is the outer diameter and also because the vessels expand due to coagulated blood within the RIJV when performing vascular measurements. Another possible factor is the limited number of subjects studied.

Tailounie et al. [9] concluded that the diameter of the IJV measured by ultrasound increases according to the gestational age of newborns, which is consistent with that observed in the present study.

It is noteworthy that a little studied characteristic in low birth weight newborns is the depth from the skin to the vein, i.e., the distance from the skin to the anterior wall of the RIJV. In this study, the overall median distance was $3.6 \mathrm{~mm}$. We observed a statistically significant difference in vessel depth, which was greater in LBW and VLBW populations when compared with ELBW newborns. No difference in the depth of the RIJV was observed between LBW compared with VLBW newborns. We believe that this parameter is important to avoid injury to adjacent structures, because the RIJV is very superficial. Alderson et al. [10] reported a correlation between RIJV depth and patient weight, similar to that observed in our study population.

Traditionally, for puncture of the internal jugular vein, the head is rotated to the contralateral side [11]. With regard to the location of the RIJV and the CA observed in the present study, in the $40^{\circ}$ position, the most frequent location was lateral $(69 \%)$, followed by anterolateral $(21 \%)$. ELBW newborns most frequently presented a lateral location (82\%).

An increase in overlapping of the RIJV and the CA has been reported in $79-86 \%$ when rotating the head from the neutral position to $45^{\circ}-60^{\circ}$ suggesting a greater likelihood of puncture of the CA $[10,12]$.

According to reports in the literature, anatomic factors are among the causes of failure of percutaneous insertion of a CVC, since in low birth weight newborns, the different muscle and bone reference points are often difficult to palpate or locate [9]. It is in these populations where vascular assessment becomes important; however, the lack of technology such as the use of ultrasound, many times, makes this assessment impossible.

\section{Conclusions}

The major advantage of ultrasonographic assessment of the RIJV in low birth weight newborn population is adequate visualization of the structures before the puncture. With it, one can measure depth, vein diameter, intraluminal conditions (patency), and determine anatomic variations and the relationship of the vein with the ipsilateral CA. Knowing the AP diameter of the RIJV in low birth weight newborns, allows proper selection of the intravascular catheter to be placed. In this study of low birth weight newborns, the diameter and depth of the RIJV is directly proportional to the patients' weight. The lateral position of the RIJV with respect to the $\mathrm{CA}$ is the most common.

\section{Acknowledgements}

We thank Sergio Lozano-Rodriguez, M.D. for his help in translating and editing the article.

\section{Declaration of Interest}

The authors report no conflicts of interest. The authors alone are responsible for the content and writing of this article.

\section{References}

1. Johnson EM, Saltzman DA, Suh G, et al. Complications and risks of central venous catheter placement in children. Surgery 1998;124: 911-16.

2. Bagwell CE, Salzberg AM, Sonnino RE, Haynes JH. Potentially lethal complications of central venous catheter placement. J Pediatr Surg 2000;35:709-13.

3. Ramasethu J. Complications of vascular catheters in the neonatal intensive care unit. Clin Perinatol 2008;35:199-222.

4. Detaille T, Pirotte T, Veyckemans F. Vascular access in the neonate. Best Pract Res Clin Anaesthesiol 2010;24:403-18.

5. Hermansen MC, Hermansen MG. Intravascular catheter complications in the neonatal intensive care unit. Clin Perinatol 2005;32: $141-56$.

6. Donaldson JS. Pediatric vascular access. Pediatr Radiol 2006;36: 386-97.

7. Smith VC. The high-risk newborn: anticipation, evaluation, management, and outcome. In: Cloherty JP, Eichenwald EC, Hansen AR, Stark AR, eds. Manual of neonatal care, 7th ed. Philadelphia, PA: Lippincott Williams \& Wilkins a Wolters Kluver business. pp. 74-90.

8. Eifinger F, Brisken K, Roth B, Koebke J. Topographical anatomy of central venous system in extremely low-birth weight neonates less than 1000 grams and the effect of central venous catheter placement. Clin Anat 2011;24:711-16.

9. Tailounie M, Mcadams LA, Frost KC, et al. Dimension and overlap of femoral and neck blood vessels in neonates. Pediatr Crit Care Med 2012;13:312-17.

10. Alderson PJ, Burrows FA, Stemp LI, Holtby HM. Use of ultrasound to evaluate internal jugular vein anatomy and to facilitate central venous cannulation in paediatric patients. Br J Anaesth 1993;70:145-48.

11. Korshin J, Klauber PV, Christensen V, Skovsted P. Percutaneous catheterization of the internal jugular vein. Acta Anaesthesiol Scand Suppl 1978;67:27-33.

12. Arai T, Matsuda Y, Koizuka K, Yasuoka A. Rotation of the head might not be recommended for internal jugular puncture in infants and children. Paediatr Anaesth 2009;19:844-47.

\section{Notice of Correction:}

The version of this article published online ahead of print on 03 MAY 2013 was missing the declaration of interest section. A statement declaring no conflicts of interest has been inserted for this version. 